www.jmscr.igmpublication.org

Index Copernicus Value: 79.54

ISSN (e)-2347-176x ISSN (p) 2455-0450

crossref DOI: https://dx.doi.org/10.18535/jmscr/v7i5.56

\title{
Role of USG in Measurement of the Thickness of Axillary Recess in Asymptomatic Shoulder and Various Shoulder Pathology
}

\author{
Authors \\ Poonma Ram ${ }^{1 *}$, R. N. Gehlot ${ }^{2}$, Kirti Chaturvedy ${ }^{3}$, Neeraj Mehta ${ }^{4}$, K. Raichandani ${ }^{5}$, \\ Prateek Sihag $^{6}$, Vipin Choudhary ${ }^{7}$ \\ ${ }^{1}$ PG MD Resident (Radiodiagnosis), ${ }^{2}$ Professor (Radiodiagnosis) \\ ${ }^{3}$ Professor and Head (Radiodiagnosis), ${ }^{4}$ Assistant Professor (Radiodiagnosis), ${ }^{5}$ Professor (Orthopedics) \\ ${ }^{6}$ Assistant Professor (Radiodiagnosis), ${ }^{7} \mathrm{PG}$ MD Resident (Radiodiagnosis) \\ Department of Radiodiagnosis, Dr. S. N. Medical College, Jodhpur, Rajasthan, India \\ *Corresponding Author \\ Dr Poonma Ram \\ Email:pr.kukal15@gmail.com
}

\begin{abstract}
Purpose: Measuring the ART in asymptomatic shoulder and various shoulder pathology by USG and to analyze the factors affecting it.

Methods: One hundred patients (50 volunteers healthy in which 30 males and 20 females and 50 with various shoulder pathology) and age $>20$ yrs.Two physiatrists (novice and experienced ratter) measured the AR thickness independently in an upright sitting position with elbow flexed and forearms in neutral position with transducer was placed longitudinally on the mid-axillary line.

Results: Mean AR thickness in asymptomatic shoulders $2.00 \pm 0.36 \mathrm{~mm}$ and in males was significantly greater $(2.21 \pm 0.33 \mathrm{~mm})$ than that in females $(1.69 \pm 0.04 \mathrm{~mm})(P<0.05$.).In our study adhesive capsulitis with DM mean ART $4.36 \pm 0.00 \mathrm{~mm}$ which is greater than without DM $(3.86 \pm 0.22 \mathrm{~mm})$. No difference between the dominant and the non-dominant sides shoulders and between the left and the right sides for sex in ART measurement. Mean AR thickness correlated positively with anthropometric variables, height $(r=0.136)$ and the weight $(r=0.140)$.

Conclusion: Mean AR thickness in healthy subjects correlated positively with anthropometric variables. The mean AR thickness in males was significantly greater than females. In symptomatic there is significant difference in AR thickness between novice and experience rater. Adhesive capsulitis with DM have ART is greater than without DM. No difference in ART in left and the right side for sex and dominant and the nondominant sides shoulders.

Keywords: Shoulder, Axilla, Ultrasonography.
\end{abstract}

\section{Introduction}

Sonography is indisputably the primary imaging modality, because of its widespread availability less costly, less invasive, high-resolution in the detection of shoulder pathology.
The axillary recess, a pouch of the glenohumeral capsule evolving from the inferior rim of the glenoid cavity to the inferior part of the humeral head. $^{7,12}$ 
Frozen shoulder (FS), is common and painful condition associated with the limitation of motion. ${ }^{3}$ The risk factors include female, trauma, age above 40 yrs, diabetes, prolonged immobilization, thyroid disease, stroke, autoimmune disease. ${ }^{3,4}$ Capsular and synovial inflammation and thickening and contraction of the shoulder joint capsule and surrounding synovium. ${ }^{5}$

Adhesive capsulitis presentation into three stages: 1- Freezing: painful stage 2. Frozen 3. Thawing stage. On USG echogenic abnormal soft tissue thickening ${ }^{11,13}$

Calcific tendinitis is a self-limiting condition due to deposition of calcium within tendons. Most common in the supraspinatus tendon leading to fibro cartilaginous metaplasia and secondary mineralization. ${ }^{25}$ The condition passes through four stages-Pre-calcific, calcific or formative, restorative and postcalcific. On ultrasound show curvilinear/ovoid calcification with acoustic shadowing and capsular soft tissue thickening.

Rotator cuff tears (cause trauma, impingement, and degeneration) are one of the most common causes of shoulder pain mostly in older patients. When the supraspinatus tendon completely ruptured then retracted and retracted tendon end is not visualized ${ }^{22,23}$ Subtypes of tears-full thickness rotator cuff tear, complete tear, partial thickness rotator cuff tear (bursal surface tear, articular surface tear).

Full-thickness appear on ultrasound as hypoechoic/ anechoic defects in the tendon. Discontinuity in tendon and non -visualization of supraspinatus tendon is direct sign of tear. The presence of tendon defect filled with fluid is most direct sign of rotator cuff tear. ${ }^{23}$

Charcot neuroarthropathy, is a chronic, degenerative arthropathy and is associated with decreased sensory innervations and most common being diabetes, syphilis, and syringomyelia.

Acromioclavicular (AC) joint instability is another indication for dynamic US. Most likely, the fluid is pooled in the axillary pouch because of gravity when the patient is in sitting position.

\section{Materials and Methods}

Patients-One hundrend subjects (50 volunteers healthy in which 30 males and 20 females and 50 with various shoulder pathology in which 40 males and 10 females) with unilateral or bilateral shoulder pain and may be right or left or mixed dominant (age >20 yrs). Right shoulders dominant (34) in which 20 males and 14 females. Left shoulders dominant (7) in which 4 males and 3 females. Mixed dominant (9) in which 6 males and 3 females. Patients with frozen shoulder (AC), partial or full-thickness rotator cuff tendon tear or calcific tendinitis arthritis, osteoarthritis, neurological disorders of the upper limbs were also enrolled in the study.

\section{Excluded patients}

Previous history of shoulder or cervical spine surgery.

US Measurement and Procedure

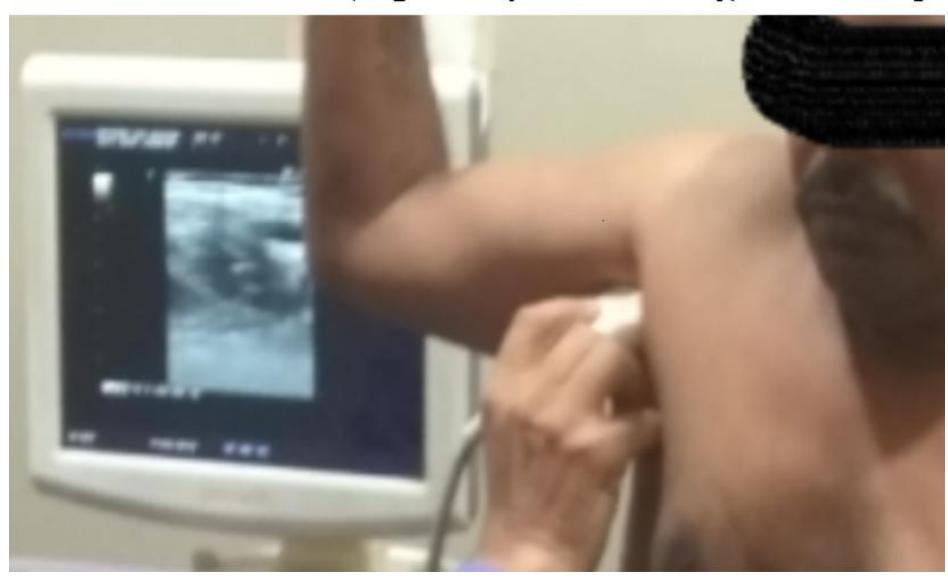

Fig-(Source-Department of Radiodiagnosis, DR S.N. Medical College, Jodhpur)

Fig. Measurement of the axillary recess thickness by USG.

The ART was measured using US in the upright sitting position with shoulder abduction angles (90o), elbow flexed and forearms were neutral with transducer was placed longitudinally on the mid-axillary line. The ART measured perpendicularly in the thickest AR portion in the middle of the humeral surgical neck concavity by two physiatrists (novice and experienced ratter).

Statistical Analysis- Statistical analysis was performed using SPSS (software package for management and statically analysis) ver. 24.0 (IBM Co., Armonk, NY, USA) with the 
significance level set at $\mathrm{p}<0.05$. An independent " $\mathrm{t}$ " test was used for assessing the ART difference between males and females, right and left sided shoulders, dominant and non dominant for both sex. Pearson's correlation coefficient used for ART between anthropometric variation.

\section{Observations and Results}

Study was done in the department of radiodiagnosis, Dr. S. N. M.C. and Associated Group of Hospitals, Jodhpur, Rajasthan, India. In our study mean ART correlated positively with anthropometric variables, height $(\mathrm{r}=0.136)$ and the weight $(r=0.140)$ BMI in healthy subjects and did not correlate with age. Mean ART on US in asymptomatic shoulders $2.00 \pm 0.36 \mathrm{~mm}$. The mean ART $(2.21 \pm 0.33 \mathrm{~mm})$ in males greater than in females $(1.69 \pm 0.04 \mathrm{~mm})$. Adhesive capsulitis with DM mean ART 4.36 \pm 0.00 which is greater than without DM mean ART 3.86 \pm 0.22 .No difference between the dominant and the nondominant sides shoulders for ART measurements ( $\mathrm{p}$ value $>.05$ ) and the left and the right sides for sex. (In male right side $2.18 \pm 0.32 \mathrm{~mm}$ and on left side $2.23 \pm 0.36 \mathrm{~mm}$ and in female right side 1 $.70 \pm 0.06 \mathrm{~mm}$ and in left side $1.68 \pm 0.04 \mathrm{~mm}$.). In symptomatic shoulders there is significant difference in AR thickness measurement between novice and experice rater.

Table: 1 Correlation between frozen shoulder and diabetes in case group

\begin{tabular}{|l|c|}
\hline \multirow{2}{*}{ Type of disease } & Case group (N=13) \\
\cline { 2 - 2 } & Mean ART \\
\hline Adhesive capsulitis without DM & $3.86 \pm 0.22$ \\
& 4 PATIENTS \\
\hline Adhesive capsulitis with DM & 9 PATIENTS \\
& $4.36 \pm 0.00$ \\
\hline
\end{tabular}

Table: 2 AR thickness in gender in asymptomatic shoulder (control group)

\begin{tabular}{|l|c|c|c|}
\hline AR thickness & Male & Female & Total (50) \\
\hline $\begin{array}{l}\text { Mean AR } \\
\text { thckness(mm) }\end{array}$ & $2.21 \pm 0.33$ & $1.69 \pm 0.04$ & $2.00 \pm 0.36$ \\
\hline
\end{tabular}

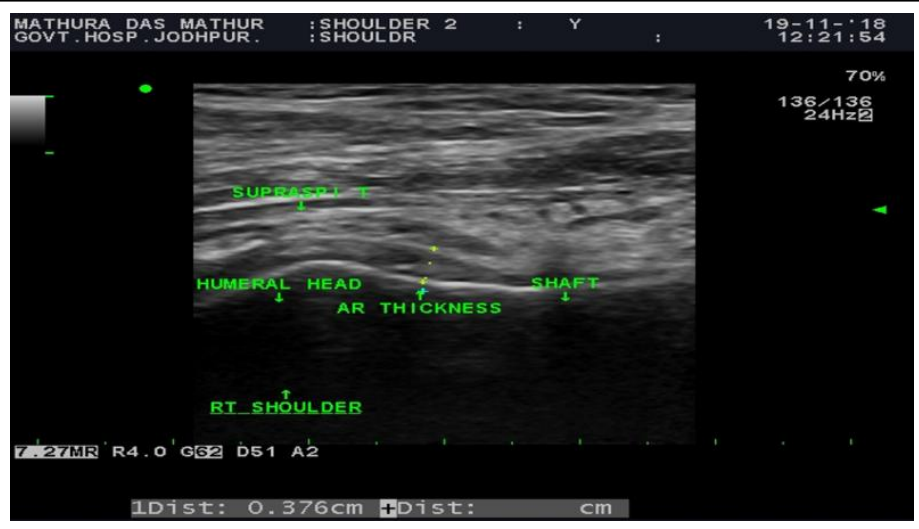

Fig 1 Representing image showing USG Measurement of the ART in symptomatic patient $(\sim 3.76 \mathrm{~mm})$.

\section{Graph-1 -Correlation between frozen shoulder and diabetes in case group}

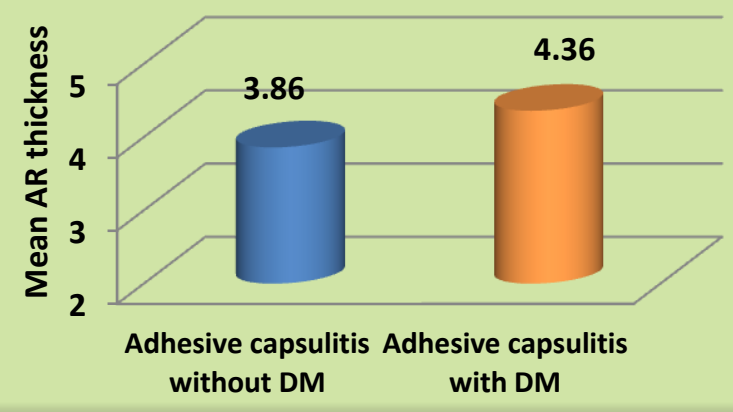

Table: 3 Correlation between the AR thickness in Asymptomatic shoulder with anthropometric parameters [control group]

\begin{tabular}{|l|c|c|c|c|}
\hline Parameters & Age & BMI & Height & Weight \\
\hline $\begin{array}{l}\text { R value (Correlation } \\
\text { coefficient ) }\end{array}$ & -0.275 & 0.168 & 0.136 & 0.140 \\
\hline
\end{tabular}

\section{Discussion}

US are most useful tools in the diagnosis of shoulder diseases and superior in comparison with MRI include better visualization of the rotator cuff $\&$ cost effective, widely available, faster examination and dynamic assessment. MRI cannot be performed bilaterally. US can measure AR thickness up to $0.1 \mathrm{~mm} \&$ no need contrast. AR thickness on US in asymptomatic was $2.00 \pm$ $0.36 \mathrm{~mm}$.

Emig et al. ${ }^{(8)}$ reported that the mean ART was 2.9 $\mathrm{mm}$ (range, 2.0 to $3.8 \mathrm{~mm}$ ) in a normal shoulder by method of Manton .Previous studies proposed 
the usefulness of AR thickness measurement using MRI for the diagnosis of FS ${ }^{8,11 .}$

Manton et al. ${ }^{(11)}$ reported that capsular and synovial thickness and joint volume were inconclusive as MR arthrography.US possesses advantages over MRI as AR is folded and redundant in the neutral position so can be overestimated and stretched with a lateral elevation of an arm (best method ). ${ }^{12}$

Other MRI studies measured each portion ofthe humeral and glenoid aspects of the $\mathrm{AR}^{11,13}$. $\mathrm{AR}$ thickness is not recommended as a good diagnostic indicator for FS. ${ }^{11}$

Out of 50 patient, 13 patients clinically diagnosis as FS. The AR thickness measured as the total thickness of the glenoid and humeral capsules. ${ }^{8,13}$ Jung et al. measured the thickness of the glenoid and humeral capsules separately. ${ }^{19}$ Eleven $^{(11)}$ patients have recurrent shoulder dislocation and 21 patients have diffuse shoulder pain and 5 patients have rotator cuff tears in which 4 patients have difficult in abduction $\left(<30^{0}\right)$ with restrictive movements and have fluid collection in joint cavity, so, proper AR thickness measurement not possible.

Out of 13 (adhesive capsulitis) patients 4 patients have diabetes and 9 patients without diabetes.

In our study adhesive capsulitis with DM (4 patients) mean ART $4.36 \pm 0.00$ which is greater than without DM (9 patients) mean ART $3.86 \pm 0.22$.

In asymptomatic shoulders (50) 34 volunteers have right shoulder dominant $(\mathrm{M}=20, \mathrm{~F}=14)$ and 9 have mixed dominant $(\mathrm{M}=6, \mathrm{~F}=3), 7$ with left dominant (M-6,F=3).

In our study there is no difference between the dominant and the non-dominant sides shoulders for ART measurements ( $\mathrm{p}$ value >.05). These study are similar to Gi-Young Park, Jin Hoon Lee, Dae Gil Kwon- (7).

In our study there is no difference ( $p$ value $>0.05$ ) between the left and the right sides in males and females for sex ART measurement. (In male right side $2.18 \pm 0.32 \mathrm{~mm}$ and on left side $2.23 \pm$ $0.36 \mathrm{~mm}$ and in female right side $1.70 \pm 0.06 \mathrm{~mm}$ and in left side $1.68 \pm 0.04 \mathrm{~mm}$.) These our study are similar to Gi-Young Park, Jin Hoon Lee, Dae Gil Kwon ${ }^{(7)}$.

In symptomatic shoulders there is significant difference in AR thickness measurement between novice and experience rater, but in asymptomatic shoulder there is no significant difference between novice and experienced rater. The mean AR thickness was significantly greater in men than in women. The mean AR thickness $(2.21 \pm 0.33 \mathrm{~mm})$ in males was significantly greater than that in females $\quad(1.69 \pm 0.04 \mathrm{~mm}) \quad(\mathrm{P}<0.05$.$) . The US$ measurement of the AR thickness correlated positively with the height and weight in all subjects. These study are similar to Gi-Young Park, Jin Hoon Lee, Dae Gil Kwon ${ }^{(7)}$ and Kyoung Tae, Dong Gyu Lee, So young, Du Hwan Kim et al. $^{12 .}$

\section{Limitations}

On US ART could not measure in the neutral position of the shoulder, inrestricted movements, unable to sit, fluid collection due to tears or chronic pathology .

\section{Conclusion}

Adhesive capsulitis with DM mean ART is greater than without DM. ART in males was significantly greater than that in females $(\mathrm{P}<0.05$ and correlated positively with anthropometric variables in healthy subjects .In symptomatic shoulders there is significant difference in AR thickness measurement between novice and experience rater, but in asymptomatic shoulder there is no significant difference between novice and experienced rater. No difference ( $\mathrm{p}$ value $>0.05$ ) between the left and the right side for gender and for dominantity.

Clinical application-USG evaluation of shoulder is an excellent non-invasive investigation for various shoulders pathology and ART measurement by USG give best correlation and helpful in planning of treatment and follow up.

Funding: No funding sources 
Conflict of interest: None declared

Ethical approval: The study was approved by the Institutional Ethics Committee.

\section{References}

1. Teefey SA, Middleton WD, Yamaguchi K. Shoulder sonography: state of the art. RadiolClin North Am 1999; 37:767-785.

2. Bouffard JA, Lee SM, Dhanju J. Ultrasonography of the shoulder. Semin Ultrasound CT MR 2000; 21:164-191.

3. Hsu JE, Anakwenze OA, Warrender WJ, Abboud JA. Current review of adhesive capsulitis. J Shoulder Elbow Surg 2011;20:502-514.

4. Neviaser JS. Adhesive capsulitis of the shoulder: a study of the pathological findings in periarthritis of the shoulder. $\mathbf{J}$ Bone Joint Surg Am 1945;27:211-222.

5. Lee MH, Ahn JM, Muhle C, Kim SH, Park JS, Kim SH, et al. Adhesive capsulitis of the shoulder: diagnosis using USG and magnetic resonance arthrography, with arthroscopic findings as the standard. J Comput Assist Tomogr2003;27:901-906.

6. Koski JM. Validity of axillary ultrasound scanning in detecting effusion of the glenohumeral joint. Scand J Rheumatol 1991;20:4951

7. Gi-Young Park, JinHoon Lee, Dae Gil Kwon-Ultrasonographic measurement of the axillary recess thickness in an asymptomatic shoulder.(2016) Department of Rehabilitation Medicine, Catholic University of Daegu School of Medicine, Daegu, Korea

8. Emig EW, Schweitzer ME, Karasick D, Lubowitz J. Adhesivecapsulitis of the shoulder: MR diagnosis. AJR Am J Roentgenol1995; 164:1457-1459.

9. Pal B, Anderson J, Dick WC, Griffiths ID. Limitation of joint mobility and shoulder capsulitis in insulin- and non-insulindependent diabetes mellitus. $\mathrm{Br} \quad \mathrm{J}$ Rheumatol
10. Tamai K, Akutsu M, Yano Y. Primary frozen shoulder: brief review of pathology and imaging abnormalities. J Orthop Sci2014;19:1-5

11. Manton GL, Schweitzer ME, Weishaupt D, Karasick D. Utility of MR arthrography in the diagnosis of adhesive capsulitis. Skeletal Radiol2001;30:326-330.

12. Kyong taekim ,soyong lee ,Du hwankim Ultrasonographic measurement of the thickness of axillary recess in Healthy Volunteers.2016 (502-508).

13. Ryu KN, Lee SW, Rhee YG, Lim JH. Adhesive capsulitis of the shoulder joint: usefulness of dynamic sonography. J Ultrasound Med 1993;12:445-9.

14. Ruta S, Rosa J, Navarta DA, Saucedo C, Catoggio LJ, Monaco RG, et al. Ultrasound assessment of new onset bilateral painful shoulder in patients with polymyalgia rheumatica and rheumatoid arthritis. ClinRheumatol2012;31:1383-7.

15. Kim I, Yi JH, Lee J, Bae JH, Lim JK, Yoon JP, et al. Limited subacromial gliding of the supraspinatus tendon during dynamic ultrasonography can predict a decrease in capacity and MR arthrographic features of the shoulder joint. EurRadiol2012;22:2365-70. 22

16. Walmsley S, Osmotherly PG, Walker CJ, Rivett DA .Power Doppler ultrasonography in the early diagnosisof primary/idiopathic adhesive capsulitis: an exploratorystudy. J Manipulative Physiol Ther2013;36:428-35.

17. Bouffard JA, Lee SM, Dhanju J. Ultrasonography of the shoulder. Semin Ultrasound CT M 2000; 21:164-191.

18. Ptasznik R, Hennesy O. Abnormalities of the biceps tendon of the shoulder: sonographic findings. AJR Am J Roentgenol 1995; 164:409-414.

19. Jung JY, Jee WH, Chun HJ, Kim YS, Chung YG, Kim JM.Adhesive capsulitis 
of the shoulder: evaluation withMR arthrography. Eur Radiol2006;16:791-6

20. Farin PU, Jaroma H. The bicipital groove of the humerus: sonographic and radiographic correlation. Skeletal Radiol 1996; 25:215-219.

21. Bianchi S, Zwass A, Abdelwahab I. Sonographic evaluation of posterior instability and dislocation of the shoulder. J Ultrasound Med 1994; 13:389- 393.

22. Schydlowsky P, Strandberg C, Galatius A, Gam A. Ultrasonographic examination of the glenoid labrum of healthy volunteers. Eur J Ultrasound 1998; 8:85-89.

23. Teefey SA, RubinDA,MiddletonWD, at all .Detection and quantification of rotator cuff tears .comparison of ultrasonographic ,magnetic resonance imaging ,and arthroscopic findings .J Bone Joint Surg Am 2004;86-A;708-716

24. Schydlowsky P, Strandberg C, Galbo H, Krogsgaard M, Jorgensen U. The value of ultrasonography in the diagnosis of labral lesions in patients with anterior shoulder dislocation. Eur J Ultrasound 1998; 8:107113.

25. Uhthoff HK: Calcifying tendinitis. Ann Chir Gynaecol 85: 11-115, 1996.

26. Bosworth BM. Calcium deposits in the shoulder and subacromial bursitis, a survey of 12,122 shoulders. JAMA 1941; 116:2477-82

27. Speed CA, Hazleman BL. Calcific tendinitis of the shoulder. N Engl J Med. 1999; 340(20):1582-4.5. Ark JW, Flock TJ, Flatow EL, Bigli 